\title{
Styloid Process: What Length Is Abnormal?
}

\author{
Omair Shah ${ }^{*}{ }^{*}$, Faiz Shera, Naseer Choh, Tariq Gojwari, Fahad Shafi, Jan Suhail, \\ Musadiq Rafiq
}

\begin{abstract}
The length of the styloid process varies greatly in different populations and depends on ethnicity and geographical background. The elongated styloid process may be associated with Eagle's syndrome. Therefore, the mean normal length of the styloid process in different population groups needs to be calculated and the upper cutoff limit for elongated styloid process should be found.

The objective of the research was to evaluate the styloid process length in the Kashmiri population using multidetector computed tomography.

Materials and Methods. We retrospectively evaluated 304 patients who underwent computed tomography of the head and paranasal sinuses, and the mean styloid process length was calculated on both sides. The mean of three measurements of styloid process length was taken. The study population was grouped as follows: Group I included patients at the age of 21-30 years; Group II comprised patients at the age of 31-40 years; Group III included 68 patients at the age of 41-50 years; Group IV comprised patients $>50$ years old.

Results. The mean length of the styloid process in the studied population varied from 20 to $51 \mathrm{~mm}$ (mean $31.3 \pm 4.5 \mathrm{~mm})$. There was no significant difference in the length on both sides $(p=0.835)$. The mean length of the styloid process was $30.1 \pm 4.2 \mathrm{~mm}$ in females and $32.3 \pm 4.8 \mathrm{~mm}$ in males $(p<0.034)$. The lengths of the styloid process in different age groups were as follows: in Group I - $30.9 \pm 4.4 \mathrm{~mm}$; in Group II $31.2 \pm 4.8 \mathrm{~mm}$; in Group III - $31.6 \pm 4.3 \mathrm{~mm}$; in Group IV - $31.5 \pm 4.5 \mathrm{~mm}$.

Conclusions. The mean length of the styloid process in our population was higher as compared to many other ethnic groups. The styloid process in males was longer. The elongated styloid process on computed tomography scan should not be labeled as Eagle's syndrome unless clinical symptoms are present.
\end{abstract}

\section{Keywords}

Styloid Process; Computed Tomography; Eagle's Syndrome; Shaded Surface Display

Department of Radiology, Sher-i-Kashmir Institute of Medical Sciences Soura, Srinagar, Jammu \& Kashmir, India

*Corresponding author: shahomair133@gmail.com

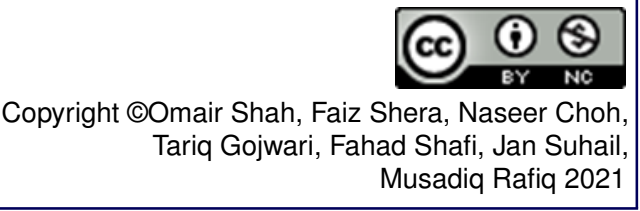

\section{Problem statement and analysis of the latest research}

The styloid process is a sharp bony projection arising from the temporal bone and projecting antero-inferiorly with a slight medial tilt. Its anatomical relations include the stylomastoid foramen posteriorly, the tonsillar fossa anteriorly, the pharyngeal wall medially, while it is flanked by the internal and external carotid arteries on each side $[1,2]$. The normal length of the process has been variably taken to be between $2-3 \mathrm{~cm}$. The styloid processes greater than $3 \mathrm{~cm}$ in length are considered as elongated and may be the symptom suggestive of Eagle's syndrome [2-6].
Embryologically, the styloid process develops from the proximal cartilage of the second pharyngeal arch which gives rise to the lesser cornu of the hyoid and the upper part of the body of the hyoid as well $[2,7]$. The elongated styloid process has been found in $14 \%$ of the population $[3,8]$. In addition, the ossification of the styloid ligament due to retaining some of its embryonic cartilage was common; however, symptoms in these patients were observed in $1-5 \%$ of cases only [7-10].

The ossification of the styloid complex varies from person to person. Depending on the patient profile, symptoms may occur in a particular individual with varying degrees of ossification of the styloid complex and different lengths of the styloid process. The most commonly reported symptoms in Eagle's 
syndrome include sore throat, odynophagia, headache and facial pain. The symptoms have been attributed to the compression of nerves and vessels in the vicinity of the styloid process $[2,11]$. Eagle's syndrome was first described by Eagle in patients undergoing tonsillectomy and having the elongated styloid process on imaging. In the original description of Eagle's syndrome, a process longer than $2.5 \mathrm{~cm}$ was taken as elongated. However, imaging evidence of the elongated styloid process alone should not be taken as an indication for treatment as the elongated styloid process may be normal anatomical variance causing no symptoms. The elongated styloid process may also cause pain in the vessels which it compresses (the internal and external carotid arteries) that is called carotodynia [12]. Rarely, the styloid process can lead to the internal jugular vein (IJV) compression and resulting venous hypertension can induce the development of dural arteriovenous fistulas [13].

Based on visualization of the styloid process, it has been classified into the following types: normal, elongated (> $25 \mathrm{~mm}$ ), pseudo articulated and segmented [13-15]. The main treatment for Eagle's syndrome is surgical resection of the elongated styloid process. Styloid process resection may also be carried out as a part of surgery for mandibular protrusion [16]. Stylo-tonsillectomy has been proposed by some centers as a safer approach with a low complication rate and earlier relief of preoperative symptoms [17]. Some centers have preferred the paratonsillar approach which is minimally invasive and can be done on a day-care basis with little postoperative complications [18]. With advances in surgery, the transoral robotic approach has also been tried in treatment of patients with Eagle's syndrome [19].

Based on the wide variations in the normal length of the styloid process, we conducted this study to obtain an overview of styloid process lengths in our population.

The objective of the research was to formulate the average value of styloid process length in our population as the values provided by previous studies cannot be applied to our population due to geographic and ethnic variations.

\section{Materials and Methods}

In this study, we evaluated computed tomography (CT) scans of the head and paranasal sinuses in 304 patients between October 2016 and December 2019. Out of 304 images evaluated, 224 were head CT scans, while the rest 80 images were paranasal sinus CT scans. The patients included in the study underwent $\mathrm{CT}$ due to trauma, headache, sinusitis/nasal blockade, and other causes not associated with the elongated styloid process. All the images that clearly showed the entire length of the styloid process were included in the study, while those in which the process was fractured due to trauma, not clearly visualized due to motion artifacts, or not fully imaged, were excluded. Any symptom that could point to carotodynia, or Eagle's syndrome, was identified and all the patients with signs suggestive of Eagle's syndrome were excluded. A total of 10 patients who were later diagnosed with Eagle's syn- drome were excluded. Among the patients in our study, there were 175 males and 129 females, and they were grouped according to age: Group I included 105 patients at the age of 21-30 years; Group II comprised 55 patients at the age of 3140 years; Group III included 68 patients at the age of 41-50 years; Group IV comprised 76 patients $>50$ years old.

All the scans in our study were done using 16-slice MDCT scanner (Siemens, Somatom). The styloid processes on both sides were fully measured after obtaining a curved multiplanar reconstruction (MPR) image by tracking the process (Fig. 1).

The final length of a particular styloid process was obtained by calculating the mean of three measurements. For comparison, the mean length of the styloid process was obtained in males and females, as well as in different age groups. A history of imaging indications and clinical symptoms was obtained from the Medical Records Department (MRD). The data obtained were evaluated using SPSS statistical software (SPSS 21, IL, USA) and expressed as mean \pm standard deviation (SD). The comparison between various age groups was done by applying the Kruskal-Wallis test. A p-value of less than 0.05 was considered to be statistically significant.

The limitations of our study included the limited number of patients with Eagle's syndrome against which a comparison could have been made to obtain a reliable cut-off value for diagnosing Eagle's syndrome.

\section{Ethical Clearance}

In view of retrospective nature of the study and no active or passive involvement of the subjects, the need for ethical clearance was waived.

\section{Informed Consent}

Informed consent was obtained from each patient by the Medical Records Department.

\section{Results}

\section{Patient Profile}

The mean patients' age in our study was $40.5 \pm 7.4$ years. The age range was 21-65 years. Out of 304 patients included in our study, $175(57.56 \%)$ were males and 129 (42.43\%) were females.

\section{Styloid Process Length}

The mean length of the styloid process in our study was $31.1 \pm 4.2 \mathrm{~mm}$ (range $20-49 \mathrm{~mm}$ ) on the right side and $31.6 \pm 4.7 \mathrm{~mm}$ (range 22-51 mm) on the left side. The size of the styloid process on both sides did not differ significantly $(p=0.835)$. When considering the mean length of the styloid process on both sides in an individual, the mean length of the styloid process in our study population varied from 20 to $51 \mathrm{~mm}$ (mean $31.3 \pm 4.5 \mathrm{~mm}$ ) (95\% confidence interval (CI) 30.8 to 31.8$)$.

The mean length of the styloid process was $30.1 \pm 4.2$ $\mathrm{mm}$ in females (Fig. 2) and $32.3 \pm 4.8 \mathrm{~mm}$ in males, and 


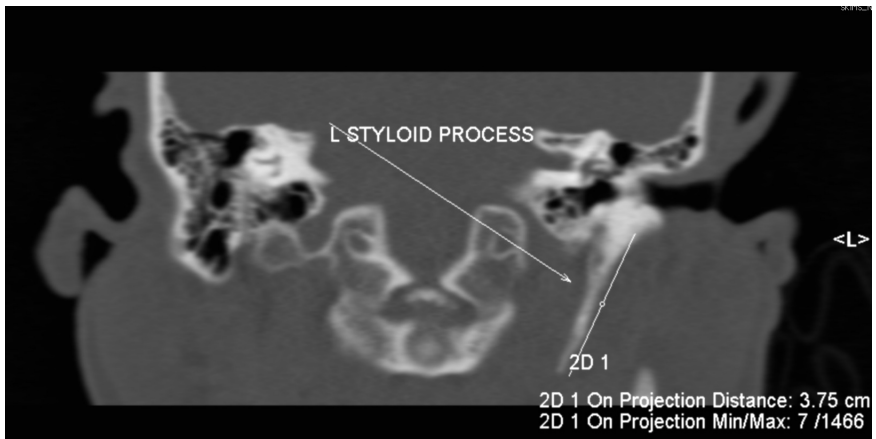

(a)

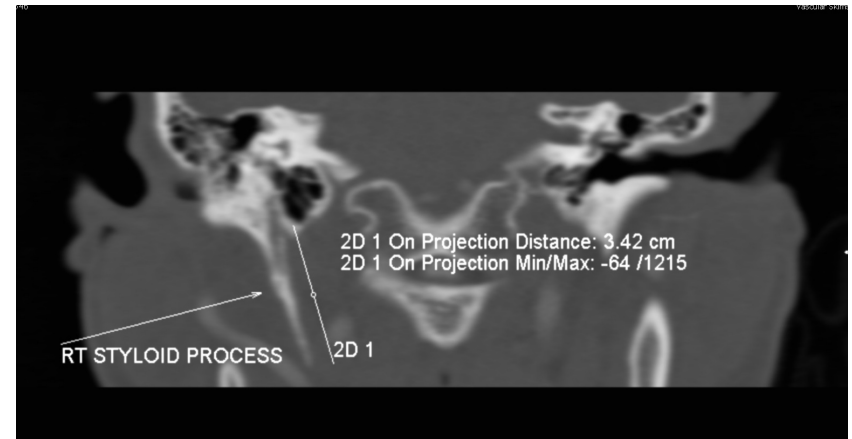

(b)

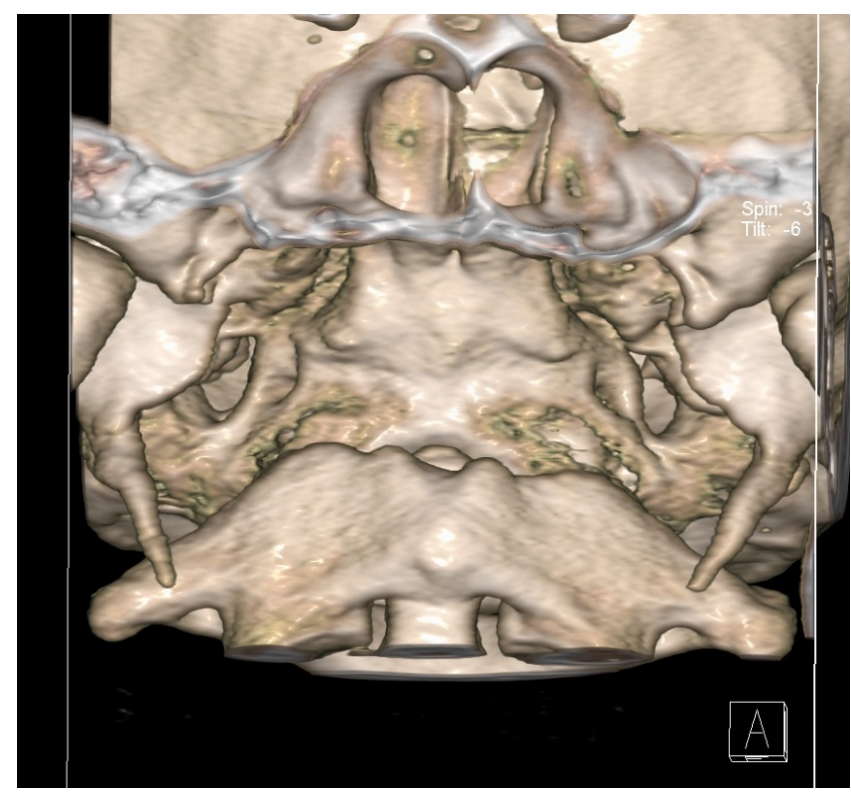

(c)

Figure 1. Curved sagittal MPR (a, b) and shaded surface display (c) images showing the length of the styloid process in a 45-year-old man.

the difference was statistically significant $(\mathrm{p}<0.034)$ (Table 1).

Table 1. Mean styloid process lengths in males and females.

\begin{tabular}{lccc}
\hline & Males & Females & $\mathrm{p}$ \\
\hline Age, years & $44.3 \pm 4.8$ & $38.7 \pm 4.0$ & $<0.001$ \\
$\begin{array}{l}\text { Mean styloid } \\
\text { length, mm }\end{array}$ & $32.3 \pm 4.8$ & $30.1 \pm 4.2$ & $<0.034$ \\
CI & $31.8-32.8$ & $29.6-30.6$ & \\
\hline
\end{tabular}

The mean lengths of the styloid process in different age groups were as follows: in Group I $-30.9 \pm 4.4 \mathrm{~mm}$; in Group II $-31.2 \pm 4.8 \mathrm{~mm}$; in Group III $-31.6 \pm 4.3 \mathrm{~mm}$; in Group IV $-31.5 \pm 4.5 \mathrm{~mm}$ (Table 2). The mean lengths in different age groups did not differ statistically $(\mathrm{p}>0.75)$.

In addition, we evaluated 10 patients who were excluded from the study due to signs of Eagle's syndrome and found that the mean length of the styloid process in these patients was $42.5 \pm 9.5 \mathrm{~mm}$ and a range of $41-58 \mathrm{~mm}$ (Fig. 3).

\section{Discussion}

Our study was aimed at evaluating the mean lengths of the styloid process in our population. We retrospectively evaluated 304 patients and calculated their mean length of the styloid process. The mean patients' age in our study was $40.5 \pm 7.4$ years. Patient profile in our study was comparable to Cullu N et al. [20] whose study included 160 patients with mean age of $37.5 \pm 6.4$ years.

In our study, we found that the mean length of the styloid process considering the mean value of the bilateral styloid processes in an individual varied from 20 to $51 \mathrm{~mm}$ (mean $31.3 \pm 4.5$ ). The mean length on the right side was $31.1 \pm 4.2$ (range 20-49) $\mathrm{mm}$ and $31.6 \pm 4.7$ (range 2251) $\mathrm{mm}$ on the left side. The lengths of the styloid pro- 


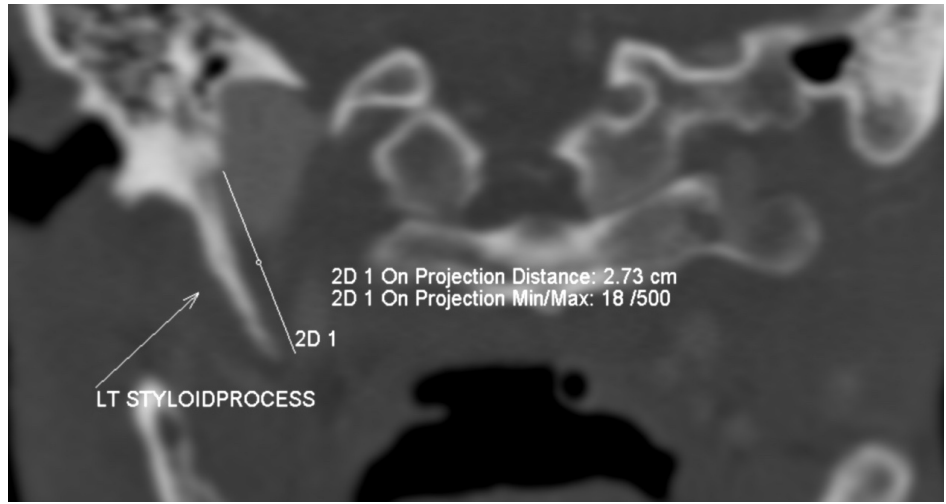

(a)

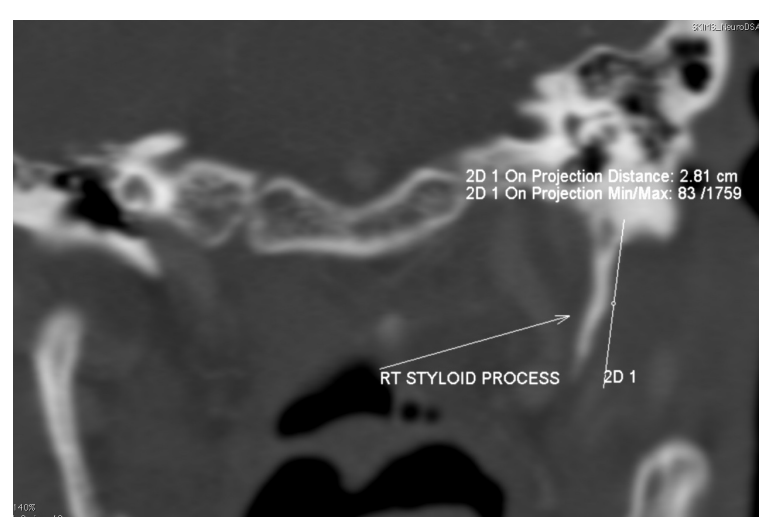

(b)

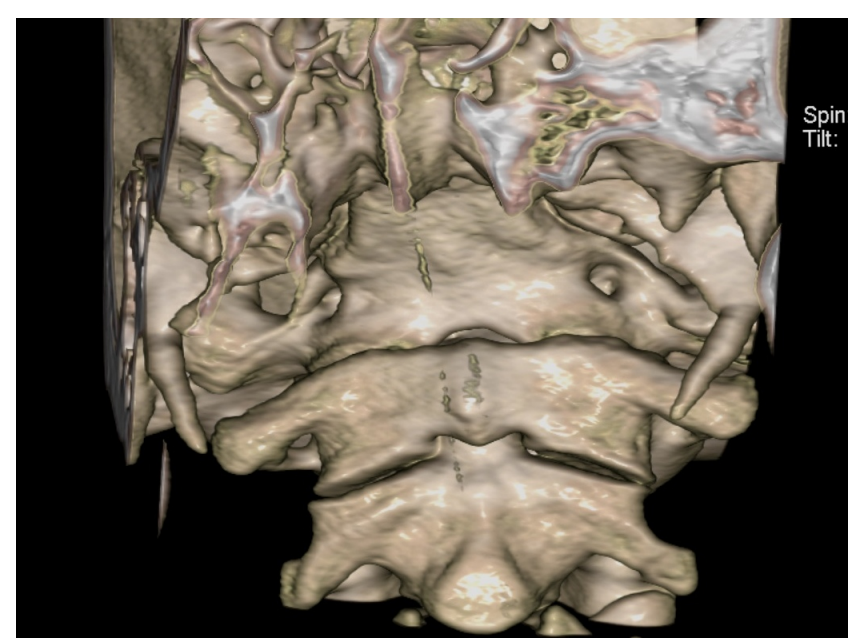

(c)

Figure 2. Curved coronal MPR (a, b) and shaded surface display (c) images showing the length of the styloid process in a 32-year-old woman.

Table 2. Mean styloid process lengths in different age groups.

\begin{tabular}{lccccc}
\hline & Group I & Group II & Group III & Group IV & p \\
\hline Mean styloid length, mm & $30.9 \pm 4.4$ & $31.2 \pm 4.8$ & $31.6 \pm 4.3$ & $31.5 \pm 4.5$ & 0.53 \\
CI & $30.4-31.4$ & $30.7-31.7$ & $31.1-32.1$ & $31.0-32.0$ & \\
\hline
\end{tabular}

cess on both sides in an individual were comparable ( $\mathrm{p}=$ 0.835). In females, the mean length of the styloid process was $30.1 \pm 4.2 \mathrm{~mm}$, while in males, it was about $32.3 \pm 4.8$ $\mathrm{mm}$. This was contrary to the fact that Eagle's syndrome is more common in females. The difference in the length between genders was statistically significant $(\mathrm{p}<0.034)$. Our results were in concordance with the findings provided by Cullu N et al. [20], who found that the mean length of the styloid process was $28.4 \pm 5.5 \mathrm{~mm}$. They found a statistically significant difference $(\mathrm{p}<0.028)$ in the mean length of the styloid process between males $(29.2 \pm 5.6 \mathrm{~mm})$ and females $(27.2 \pm 5.2 \mathrm{~mm})$. Our results matched those obtained by Ekici F et al. [21], who found that the styloid processes were longer in males $(33.2 \pm 13.2 \mathrm{~mm})$ as compared to females
$(29.6 \pm 10.5 \mathrm{~mm})(\mathrm{p}<0.001)$. The mean length in their study was $31.2 \pm 11.9 \mathrm{~mm}$. According to Yetiser S et al. [22], the mean lengths of the styloid processes varied from 20 to $32 \mathrm{~mm}$. Yavuz H et al. [23], who conducted the study among Turkish population, found that the mean length of the styloid process was $50 \mathrm{~mm}$ and $52 \mathrm{~mm}$ on the right and left sides, respectively. The findings provided by Yavuz $\mathrm{H}$ et al. [23] were markedly different from our results which could probably be due to geographical and ethnic differences between the two populations studied. Our results showed that the length of the styloid process depended mainly on the geographical and ethnic background of the population. In addition, the mean length of the styloid process in our population was marginally higher and fell within elongated styloid classification, as sug- 


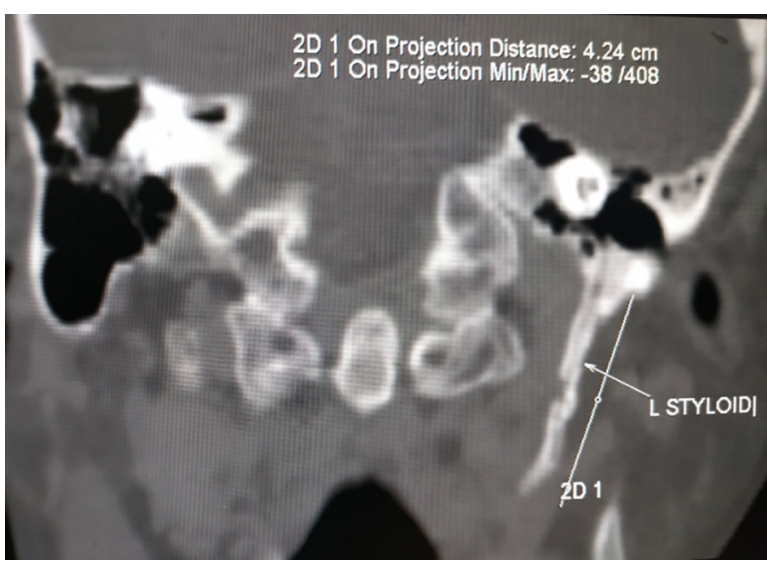

(a)

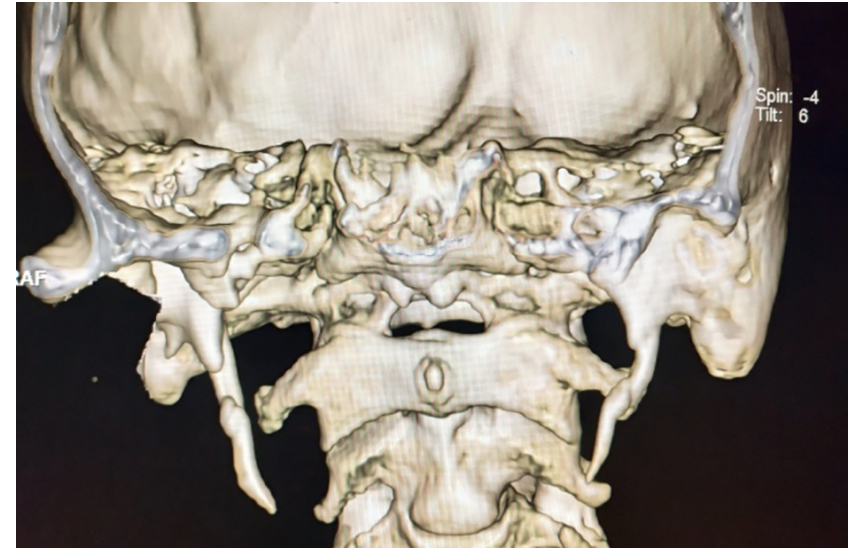

(b)

Figure 3. Curved sagittal MPR (a) and shaded surface display (b) images showing the length of the styloid process in a 36-year-old woman with clinical diagnosis of Eagle's syndrome.

gested by many researchers.

In our study, we calculated the mean length of the styloid process in different age groups and found that there was no significant difference in the mean length of the styloid process in the age range of 21 to 65 years ( $p>0.75$ ). The mean length of the styloid process in different age groups were as follows: in Group I (21-30 years) - $30.9 \pm 4.4 \mathrm{~mm}$; in Group II (3140 years) $-31.2 \pm 4.8 \mathrm{~mm}$; in Group III (41-50 years) $31.6 \pm 4.3 \mathrm{~mm}$; in Group IV ( $>50$ years $)-31.5 \pm 4.5 \mathrm{~mm}$. These findings were corroborated with the findings provided by Cullu $\mathrm{N}$ et al. [20], who calculated the mean lengths of the styloid process of people in the $3^{\text {rd }}$ and $4^{\text {th }}$ decades of life and found no statistically significant difference ( $p>0.718)$. Our results matched those obtained by Ekici F et al. [21], who found no significant difference in the lengths of the styloid process in different age groups (the $4^{\text {th }}$ and $5^{\text {th }}$ decade in their study).

In our study, we additionally evaluated 10 patients with clinical signs suggestive of Eagle's syndrome and calculated the mean length of the styloid process in these patients. We found that the mean length of the styloid process in these patients was $42.5 \pm 9.5 \mathrm{~mm}$ and a range of $41-58 \mathrm{~mm}$. Moreover, among these 10 patients, there were 7 females and 3 males, indicating a predominance of women. However, due to the smaller number of patients, we could not formulate the cutoff value that could be used for diagnosis of Eagle's syndrome. However, despite some overlap, all patients with Eagle's syndrome had the mean length of the styloid process greater than $41 \mathrm{~mm}$. Thus, in our population group, the length of the styloid process greater than $41 \mathrm{~mm}$ should raise suspicion of Eagle's syndrome, and clinical signs and symptoms should be actively sought if an incidental note of such styloid process length was made. Our findings were comparable to studies carried out by Basekim CC et al. [5], who concluded that $40 \mathrm{~mm}$ was the upper value above which Eagles syndrome could be diagnosed and Jung T et al. [24], who found a higher cutoff value of $45 \mathrm{~mm}$. However, Eagle WW [25] in his original study found $25 \mathrm{~mm}$ as the upper cutoff value to diagnose the syndrome. In addition, Ramadan SU et al. [11] obtained the cutoff value of $30 \mathrm{~mm}$ for describing the elongated styloid process. These different values again signify geographic and ethnic variations in the size of the styloid process, as well as the size that can be taken as an indicator of possibility of Eagle's syndrome.

\section{Conclusions}

The mean length of the styloid process varied widely depending on the ethnic and geographic background of the studied population. The mean length of the styloid process in our population was $31.3 \pm 4.5 \mathrm{~mm}$ with no significant variation on both sides. Males had a longer styloid process as compared to females. There was no significant variation in the length of the styloid process in different age groups (21-65 years). The length of the styloid process alone is not sufficient for diagnosing Eagle's syndrome; however, the mean length of the styloid process $>41 \mathrm{~mm}$ should raise strong suspicion of Eagle's syndrome in our population and encourage active research on associated clinical signs and symptoms.

\section{Conflict of Interest}

The authors declare that no conflicts exist.

\section{Financial Disclosure}

The authors declared no financial support.

\section{References}

[1] Yavuz H, Caylakli F, Yildirim T, Ozluoglu LN. Angulation of the styloid process in Eagle's syndrome. 
European Archives of Oto-Rhino-Laryngology [Internet]. 2008 Apr 22;265(11):1393-1396. Available from: https://doi.org/10.1007/s00405-008-0686-9

[2] Fusco DJ, Asteraki S, Spetzler RF. Eagle's syndrome: embryology, anatomy, and clinical management. Acta Neurochirurgica [Internet]. 2012 May 26;154(7):1119-1126. Available from: https://doi.org/10.1007/s00701-012$1385-2$

[3] Chourdia V. Elongated styloid process (Eagle's syndrome) \& severe headache. Indian J Otolaryngol Head Neck Surg [Internet]. 2002 Jul;54(3):238-241. Available from: http://www.ncbi.nlm.nih.gov/pubmed/23119903

[4] Ozdemir MB, Okunak M, Koseler A, Simsek C, Atalay E, Yonauc GN. An ancient anatomic variation: bilateral elongated styloid process of cranium. Ital J Anat Embryol [Internet]. 2013 Jul;118(2):184-188. Available from: http://www.ncbi.nlm.nih.gov/pubmed/25338408

[5] Başekim CÇ, Mutlu H, Güngör A, Şilit E, Pekkafali Z, Kutlay M, et al. Evaluation of styloid process by threedimensional computed tomography. European Radiology [Internet]. 2004 Jun 19;15(1):134-139. Available from: https://doi.org/10.1007/s00330-004-2354-9

[6] Sudhakara Reddy R, Sai Kiran C, Sai Madhavi N, Raghavendra M, Satish A. Prevalence of elongation and calcification patterns of elongated styloid process in south India. Journal of Clinical and Experimental Dentistry [Internet]. 2013;5(1):e30-e35. Available from: https://doi.org/10.4317/jced.50981

[7] Last RJ, McMinn RHM. Last's anatomy, regional and applied. 9th ed. Edinburgh ; New York : Churchill Livingstone; 1994.

[8] Patil S, Ghosh S, Vasudeva N. Morphometric Study of the Styloid Process of Temporal Bone. Journal of Clinical and Diagnostic Research [Internet]. 2014;8(9):AC04-AC06. Available from: https://doi.org/10.7860/JCDR/2014/9419.4867

[9] Bozkir MG, Boga H, Dere F. The Evaluation of Elongated Styloid Process in Panoramic Radiographs in Edentulous Patients. Turkish Journal of Medical Sciences. 1999;29:481-485. Available from: https://dergipark.org.tr/en/download/article-file/129820

[10] Gözil R, Yener N, Çalgüner E, Araç M, Tunç E, Bahcelioğlu M. Morphological characteristics of styloid process evaluated by computerized axial tomography. Annals of Anatomy - Anatomischer Anzeiger [Internet]. 2001 Nov;183(6):527-535. Available from: https://doi.org/10.1016/S0940-9602(01)80060-1
[11] Ramadan SU, Gokharman D, Tunçbilek I, Kacar M, Koşar P, Kosar U. Assessment of the stylohoid chain by 3D-CT. Surgical and Radiologic Anatomy [Internet]. 2007 Jul 27;29(7):583-588. Available from: https://doi.org/10.1007/s00276-007-0239-8

[12] Som PM, Curtin HD. Head and Neck Imaging. Fourth edition. Mosby; 2003. 2322 p.

[13] Suzuki Y, Toma N, Kuroda Y, Miura Y, Shiba M, Yasuda R, et al. Dural Arteriovenous Fistula Formation as Eagle Jugular Syndrome: A Case Report and Literature Review. World Neurosurgery [Internet]. 2020 Dec;144:154-161. Available from: https://doi.org/10.1016/j.wneu.2020.08.214

[14] Langlais R, Langland O, Nortje C. Diagnostic imaging of the jaws. Baltimore: Williams \& Wilkins; 1995.

[15] Guimarães SMR, Carvalho ACP, Guimarães JP, Gomes MB, Cardoso M de MM, Reis HN. Prevalência de alteração morfológica do processo estilóide em pacientes com desordem temporomandibular. Radiologia Brasileira [Internet]. 2006 Dec;39(6):407-411. Available from: https://doi.org/10.1590/S0100-39842006000600007

[16] Shimizu T, Yokoo S, Takayama Y, Musha A, Ogawa M, Makiguchi T. Elongated Styloid Process With Skeletal Mandibular Protrusion. Journal of Craniofacial Surgery [Internet]. 2020 Dec 9;Publish Ahead of Print. Available from: https://doi.org/10.1097/SCS.0000000000007298

[17] Ravisankar M, Murugesan GS. Evaluation of Eagle's Syndrome and Assessment of Post-operative Outcome of Excision of Elongated Styloid Process: A Prospective Study, in Tertiary Care Centre, India. Indian Journal of Otolaryngology and Head \& Neck Surgery [Internet]. 2020 Nov 16. Available from: https://doi.org/10.1007/s12070-02002255-4

[18] Govindarajalu P, Sharma Y, Parsana M. Paratonsilar Approach to Styloid Process in Eagle's Syndrome-A Retrospective Analysis. Indian Journal of Otolaryngology and Head \& Neck Surgery [Internet]. 2020 Oct 1 . Available from: https://doi.org/10.1007/s12070-020-02183-3

[19] Rizzo-Riera E, Rubi-Oña C, García-Wagner M, Costa AA-D, Miralles J, Enchev E, et al. Advanced Robotic Surgery of the Parapharyngeal Space. Journal of Craniofacial Surgery [Internet]. 2020;31(8):2339-2341. Available from: https://doi.org/10.1097/SCS.0000000000006804

[20] Cullu N, Deveer M, Sahan M, Tetiker H, Yilmaz M. Radiological evaluation of the styloid process length in the normal population. Folia Morphol (Warsz) [Internet]. 2013 Dec 4;72(4):318-321. Available from: https://doi.org/10.5603/FM.2013.0053 
[21] Ekici F, Tekbas G, Hamidi C, Onder H, Goya C, Cetincakmak MG, et al. The distribution of stylohyoid chain anatomic variations by age groups and gender: an analysis using MDCT. European Archives of Oto-RhinoLaryngology [Internet]. 2012 Oct 7;270(5):1715-1720. Available from: https://doi.org/10.1007/s00405-012$2202-5$

[22] Yetiser S, Gerek M, Ozkaptan Y. Elongated Styloid Process: Diagnostic Problems Related to Symptomatology. CRANIO® [Internet]. 1997 Jul;15(3):236-241. Available from: https://doi.org/10.1080/08869634.1997.11746017

[23] Yavuz H, Caylakli F, Yildirim T, Ozluoglu LN. Angulation of the styloid process in Eagle's syndrome. European Archives of Oto-Rhino-Laryngology [Internet]. 2008 Apr 22;265(11):1393-1396. Available from: https://doi.org/10.1007/s00405-008-0686-9
[24] Jung $\mathrm{T}$, Tschernitschek H, Hippen H, Schneider B, Borchers L. Elongated styloid process: when is it really elongated? Dentomaxillofacial Radiology [Internet]. 2004 Mar;33(2):119-124. Available from: https://doi.org/10.1259/dmfr/13491574

[25] Eagle WW. Elongated Styloid Process: Symptoms and Treatment. Archives of Otolaryngology - Head and Neck Surgery [Internet]. 1958 Feb 1;67(2):172-176. Available from: https://doi.org/10.1001/archotol.1958.00730010178007

Received: $2020-11-25$

Revised: 2020-12-26

Accepted: $2020-12-29$ 